\title{
'EYE DONATION AWARENESS' AMONG PARAMEDICAL STAFF OF DIFFERENT HOSPITALS IN RAICHUR DISTRICT: A SURVEY
}

Sameena Kokab.

1. Assistant Professor, Department of ophthalmology, Navodaya Medical College, Raichur.

\section{CORRESPONDING AUTHOR:}

Dr. Sameena Kokab, Asst Professor, Dept of Ophthalmology, Navodaya Medical College, Raichur.

Karnataka State.

E-mail: sameena_kokab@rediffmail.com

ABSTRACT: BACKGROUND: Corneal blindness is one of the most common causes of treatable blindness in India. The only treatment option available for corneal blindness is transplantation of donor corneas that are obtained through eye donation, upon a person's death. The number of corneal transplants done is far less than the actual requirement in India. This is largely due to the inadequate number of corneas collected. The Para medical professionals play an important role and can contribute by participating in creating awareness and motivating people to become eye donors.

AIM: To assess the awareness of Para medical staff from different hospitals towards eye donation. SETTING: Raichur, Karnataka, India. METHODOLOGY: Survey RESULTS: The majority of Para medical staff [ $\mathrm{n}=200]$ (94\%) was aware about Eye Donation. 90\% knew that eyes can be donated after death. The major source of information was from the mass media/ TV/radio/ movies (43.5\%).And 13.5\% knew about the ideal time for eye donation. CONCLUSION: The study revealed that Among the paramedical staff who were not willing to donate eyes the major reason was lack of interest and other reasons being weak eye sight, religious belief and afraid of invasive process. Only media publicity is not enough to increase the awareness regarding Eye Health Care and Eye Donation. It requires sustained efforts from trained paramedical personnel, NGOs and religious groups in creating awareness and motivating people. Inclusion of different preventive and curative aspects of corneal blindness along with basic eye health care into the paramedical course curriculum is the need of the hour.

KEYWORDS: Awareness, Eye Donation, Paramedical Staff

INTRODUCTION: People who are blind by corneal disease, their eye sight can be restored by corneal transplantation. In India it's been estimated that there are 18.7 million cases of blindness and among these blinds, 1, 90,000 are blind due to bilateral corneal disease [1]. Each year about 20,000 new cases of corneal blindness is added to the existing list [2]. Corneal diseases constitute a significant cause of visual impairment and blindness in the developing world [3]. Keratitis during childhood, trauma, and keratitis during adulthood resulting in a vascularized corneal scar and adherent leucoma are the most frequent causes of corneal blindness in developing countries [4]. According to the Eye Bank Association of India, the current cornea procurement rate in India is 22,000 per year. It is estimated that a significant proportion of donor corneas are unsuitable for 
corneal transplantation [5]. Based upon our current ratio of available safe donor eyes, we would need 277,000 donor eyes to perform 100,000 corneal transplants in a year in India [6]

Many cross sectional studies on awareness on eye donation has been done on medical, nursing students, as well as urban and rural population. In our study we made an attempt to study the knowledge and awareness of paramedical staff regarding eye donation. Para medical staffs are part of health care team in our community; they can play an active role in influencing eye donation in the community.

Keeping all the above mentioned points in view, an epidemiological questionnaire hospital based survey was undertaken to find out the awareness and knowledge on eye donation using a pretested questionnaire with the following objectives:

a) Socio-demographic questionnaire.

b) Structured knowledge questionnaire to elicit the knowledge regarding 'Eye donation'.

c) Attitude scale for assessing attitude towards 'eye donation'

MATERIALS AND METHODS: This study was conducted in North Karnataka, Raichur District at various hospitals including Medical, Dental teaching institutes were selected based on convenient sampling. 200 para medical staffs were included for the study on the basis of inclusion and exclusion criterion. Out of 200 there were 91 medical, 10 dental, 30 laboratory technology, 38 pharmacy, 2 biomedical and 2 bioengineering, 9 X-ray technician, 11 Medical record technician, 7 Operation theatre technicians.

\section{SAMPLING CRITERIA:}

Inclusion Criteria:

1. Para medical assistants working in the Raichur District Hospitals.

2. All were above 20 years of age.

3. Para medical assistants who can understand English, Hindi.

\section{Exclusion criteria:}

1. Para medical assistants who are working in eye bank / ophthalmologic ward.

2. Those who are not willing to participate in study.

3. Para medical assistants who are not present at the time of study.

ETHICAL CLEARANCE: The research protocol was reviewed and approved by the ethical committee of Navodaya Medical College.

OFFICIAL PERMISSION: Was obtained from:

1. Respective Hospital authorities to conduct the study.

SCHEDULING: The average time for the interview of each study subject was approximately 15 minutes. In the single day maximum of the 15 subjects were personally interviewed and data was recorded on structured questionnaire. The interviews were carried out on all the week days excluding the Sundays. The entire survey period spanned over the period of two months from May 2012 and June 2012. 
TRAINING AND CALLIBRATION OF EXAMINERS: A single trained examiner carried out the entire interview in the survey. The examiner was trained and calibrated in the Department of Ophthalmology for carrying out the interview on the pre selected subjects twice at the interval of 30 minutes. The diagnostic variability in two assessments was found to be small and agreement was found to be in the range of $85-90 \%$.

DATA COLLECTION: The data regarding the awareness and knowledge on eye donation was recorded on pretested questionnaire by the personal face to face interview of the study subjects by the single interviewer. The questionnaire was prepared both in English and Hindi containing multiple choices and closed ended type of questions.

The questionnaire recorded the information regarding the socio-demographic characteristics of the study subjects, included demographic details, individual knowledge and awareness regarding eye health care, eye donation and sources of information regarding eye donation.

STATISTICAL ANALYSIS: Collected data was entered in the Microsoft Word Excel Sheet 2007 version and the data obtained was analyzed using the SPSS (Statistical Package for the Social Sciences) 17 Version.

RESULTS: Out of 200 assistants, 107 (53.5\%) were males 93 (46.5\%) were females and. Age group ranged between 20- 50 yrs of which majority 130 (65\%) were in the age group of 21 to 30 yrs. 92\% of staff belonged to Hindu religion, 6\% were Muslim and Other religion 2\%. In the study it was observed that $94 \%$ attendants were aware about eye donation. The major source of information was from the mass media/ TV/radio/ movies (43.5\%). Noble work/ pleasure to help blind was the main motivational force according to $48.5 \%$ of the para medical staff. Reasons for not donating eyes included objection by family members, dislike of disfiguring the body, and religious restrictions. $13.5 \%$ knew about the ideal time for eye donation.

TABLE 1: Most Common Source of information on eye donation

\begin{tabular}{|l|l|l|}
\hline Source & Number & Percentage \\
\hline Mass media/TV/radio/magazine & 87 & 43.5 \\
\hline Doctor/Hospital & 22 & 11 \\
\hline Poster/Pamphlets & 48 & 24 \\
\hline Others & 17 & 8.5 \\
\hline Friends/Colleagues & 14 & 7 \\
\hline No Information & 12 & 6 \\
\hline
\end{tabular}

TABLE 2: Knowledge about Ideal Time for Eye Donation 


\section{ORIGINAL ARTICLE}

\begin{tabular}{|l|l|l|}
\hline Time & Number of Study Subject & Percentage \\
\hline Within 1 to 2 hrs & 66 & 33 \\
\hline Within 6 hrs & 27 & 13.5 \\
\hline Within 24 hours/72 hrs & 32 & 16 \\
\hline Any Time After Death & 48 & 24 \\
\hline Did not answer/left blank & 27 & 13.5 \\
\hline
\end{tabular}

TABLE 3: Distribution of perceived reasons for donating eyes by donors

\begin{tabular}{|l|l|l|}
\hline Reason & Number of Study Subject & Percentage \\
\hline Noble work/ pleasure to help blind & 97 & 48.5 \\
\hline Donated eyes can give vision to a person & 45 & 22.5 \\
\hline Influenced after reading an article/print media & 27 & 13.5 \\
\hline A friend or relative has donated an eye & 3 & 1.5 \\
\hline Influenced by any lecture/academic knowledge & 16 & 8 \\
\hline Not yet decided & 12 & 6 \\
\hline
\end{tabular}

DISCUSSION: A large proportion of corneal blindness can be avoidable or treated is avoidable [7,8,9]. Though strategies to prevent corneal blindness are more cost effective, corneal transplantation remains the major treatment option. The statistics on eye donation in India shows that there is a considerable and constantly growing backlog of corneal transplantation [10]. It is need of the hour to enhance the awareness regarding eye donation among the potential donors in an effort to increase the procurement of corneas. It is estimated that approximately 190,000 persons in India are blind from bilateral corneal disease [11]. Every year another 20,000 new cases join the existing backlog2. Even after 50 years, patients are waiting for the corneal transplantation since Dr Muthiah started the first eye bank in India and he successfully performed the first corneal transplant in 1948 [12] Majority of them are young in the productive age group who have lost their vision either due to injuries, infection/ malnutrition or were congenital in nature etc. The sight can be restored only by corneal transplantation.

In this study, 94\% of the Para medical staff was aware of eye donation. In another study among hospital staff, $97 \%$ of them had good to excellent knowledge about transplantation of various human 


\section{ORIGINAL ARTICLE}

organs [13]. In a study by Anita Gupta et al, $96.8 \%$ of the nursing students were aware that eyes could be donated after death [10]. In a study by Priyadarshan B et al, among the south Indian population, $50.7 \%$ of participants were aware of eye donation ${ }^{[14] \text {. }}$

Information by mass media was the main reason in $46.3 \%$ of Para medical staff for the high level of awareness in our study participants. Mass media in the form of television, newspapers, magazines, and posters were important sources of information on eye donation. Other studies also found publicity campaigns and the media to be the major sources of information on this issue [15-17]. The timing of eye donation is very important. If the eyes cannot be collected within 6 hours of death, they may not be utilized for optical purpose. Thus, lack of knowledge regarding optimal timing for eye donation will lead to underutilization of donated corneas [18]. In study done by Gupta A et al [10], on nursing students 32.8\% knew that the ideal time for donation is within 6 hours of death [7,12]. Similarly in a study by Dhaliwal U [19] on medical and nonmedical students also observed that 63.3\% of medical students knew that it should be done within 6 hours [13]. In a study by Suresh K et al [20], $86.3 \%$ knew about the ideal time for eye donation is within $6 \mathrm{hrs}$. In the present study the time limit to collect the cornea, $35.11 \%$ were of the opinion that the ideal time for eye donation is 1 to 2 hrs after the death of the person, 13.5\% knew the ideal time for donation is within 6 hours.

In the study the main reason to donate eyes in majority $48.5 \%$ of para medical staff was to help blind people or for the noble cause, and reasons for not donating was lack of interest among of staff and weak eye sight, religious belief, afraid of invasive process among of Para medical staff. In the study by Gupta A et $\mathrm{al}^{10}$, the main reasons for eye donation were nobility in the work by 137 (85.6\%) and pleasure to help the blind by $77.5 \% 10$. Other reasons for not donating eyes included objection by family members, dislike of disfiguring the body, delaying of religious rites, and religious restrictions. Similar reasons were also reported in other studies [15, 21].

There is a great need to educate masses, as they are an important part of our society [18]. If they are educated about the preventive and curative aspects of corneal blindness, they can spread the message among their friends and family members, thus acting as important motivators. It is also essential to remove their misconception regarding eye donation [18].

From our study few observations were made, most of the subjects were not aware whom to contact, when to contact, place of eye donation, and time limit for eye donation. Few subjects were of the opinion that, the donor's family should get monetary benefit or a job in Government services, or free health care throughout life for the donor's family. Most the subject remember the famous personality / celebrity who have pledged their eyes for eye donation and who has been on Televison advertisement. The policy makers should give a thought about these observations which will help in developing strategies to increase procurement of corneas.

CONCLUSION: Data from our study suggests that the knowledge regarding the place of eye donation, time limit to collect cornea and whom to contact and when to contact was still not known clearly. Among the attendants who were not willing to donate eyes the major reason was lack of interest and other reasons being weak eye sight, religious belief and afraid of invasive process. Only media publicity is not enough to increase the awareness regarding eye health care and eye donation. Therefore, inclusion of different preventive and curative aspects of corneal blindness along with basic eye health care into the course curriculum is the need of the hour. The lack of local eye donations should be taken seriously and measures must be taken by all the concerned governmental 


\section{ORIGINAL ARTICLE}

and non-governmental organizations to improve this situation so that needful patients can be transplanted at an affordable cost without waiting for long periods.

\section{REFERENCES:}

1. Dandona L, Dandona R, John RK. Estimation of blindness in India from 2000 through 2020: Implications for the blindness control policy. Natl Med J India 2001; 14:327-34.

2. Saini JS, Reddy MK, Jain AK, Ravinder MS, Jhaveria S,Raghuram L. Perspectives in eye banking. Indian J Ophthalmol 1996; 44:47-55.

3. Thylefors B, Negrel AD, Pararajasegaram R, Dadzie KY. Global data on blindness. Bull WHO 1995;73:16-21

4. Garg P, Krishna PV, Stratis AK, Gopinathan U. The value of corneal transplantation in reducing blindness. Eye (Lond). 2005 Oct; 19(10):1106-14.

5. Dandona R, Dandona L, Naduvilath TJ, McCarty CA, Rao GN. Awareness of eye donation in an urban population in India. Aust N Z J Ophthalmol 1999;27:166-9.

6. Saini JS. Realistic Targets and Strategies in Eye Banking. Indian J Ophthalmol 1997; 45:1412.

7. Mohan M. Survey of Blindness-India (1986-1989): Summary Results. New Delhi: Programme for the Control of Blindness, Ministry of Health and Family Welfare, Government of India; 1992.

8. Thulasiraj RD, Nirmalan PK, Ramakrishnan R, Krishnadas R, Manimekalai TK \& Baburajan NP et al. Blindness and vision impairment in a rural south Indian population: the Aravind Comprehensive Eye Survey. Ophthalmology 2003; 110: 1491-1498.

9. Dandona L, Dandona R, Srinivas M, Giridhar P, Vials K \& Prasad MN et al. Blindness in the Indian state of Andhra Pradesh. Invest Ophthalmol Vis Sci 2001; 42: 908-916.

10. Gupta A, Jain S, Jain T, Gupta K. Awareness and Perception Regarding Eye Donation in Students of a Nursing College in Bangalore. Indian Journal of Community Med 2009; 34:1225.

11. National Program for the Control of Blindness. Report of National Program for the Control of Blindness, India and World Health Organization, 1986-89.

12. Kannan KA. Eye donation movement in India. J Indian Med Assoc 1999; 97:318-9.

13. Singh P, Kumar A, Pandey CM, Chandra H. Level of awareness about transplantation, brain death and cadaveric organ donation in hospital staff in India. Prog Transplant 2002; 12:28992.

14. Priyadarshan B, Srinivasan M, Padmavathi A, Selvam R, Saradha R, Nirmalan PK. Awareness of eye donation in an adult population of southern India. A pilot study. Indian J Ophthalmol. 2003;51:101- 4

15. Tandon R, Verma K, Vanathi M, Pandey RM, Vajpayee RB. Factors affecting eye donation from post-mortem cases in a tertiary care hospital. Cornea 2004;23:597-601

16. Singh $M$ et al: Eye Donation: Perception and promoting factors among medical students. Indian J community Health 2012; 24:175- 178.

17. Singh MM, Rahi M, Pagare D, Ingle GK. Medical Student's perception on eye donation in Delhi. Indian J Ophthalmo.2007 Jan-Feb; 55(1):49-53. 
18. Biswas J etal. A study on awareness about eye health care and eye donation among secondary level students of North Kolkata, India. Kathmandu Univ Med J 2010; 8(31):31720.

19. Dhaliwal U. Enhancing eye donation rates. Training students to be motivators. Indian J Ophthalmol. 2002; 50: 209-12.

20. Suresh K, Priyanka P, Shanmugha Priya Awareness of Eye Donation in Rural and Hospitalbased Population. Indian journal of practising Doctors Ind Medica, 2008; 4, No.6

21. Phadke KD, Anandh U. Ethics of paid organ donation. Pediatr Nephrol 2002; 17:309-11.

CHART 1: Sex wise distribution of Paramedical Staff
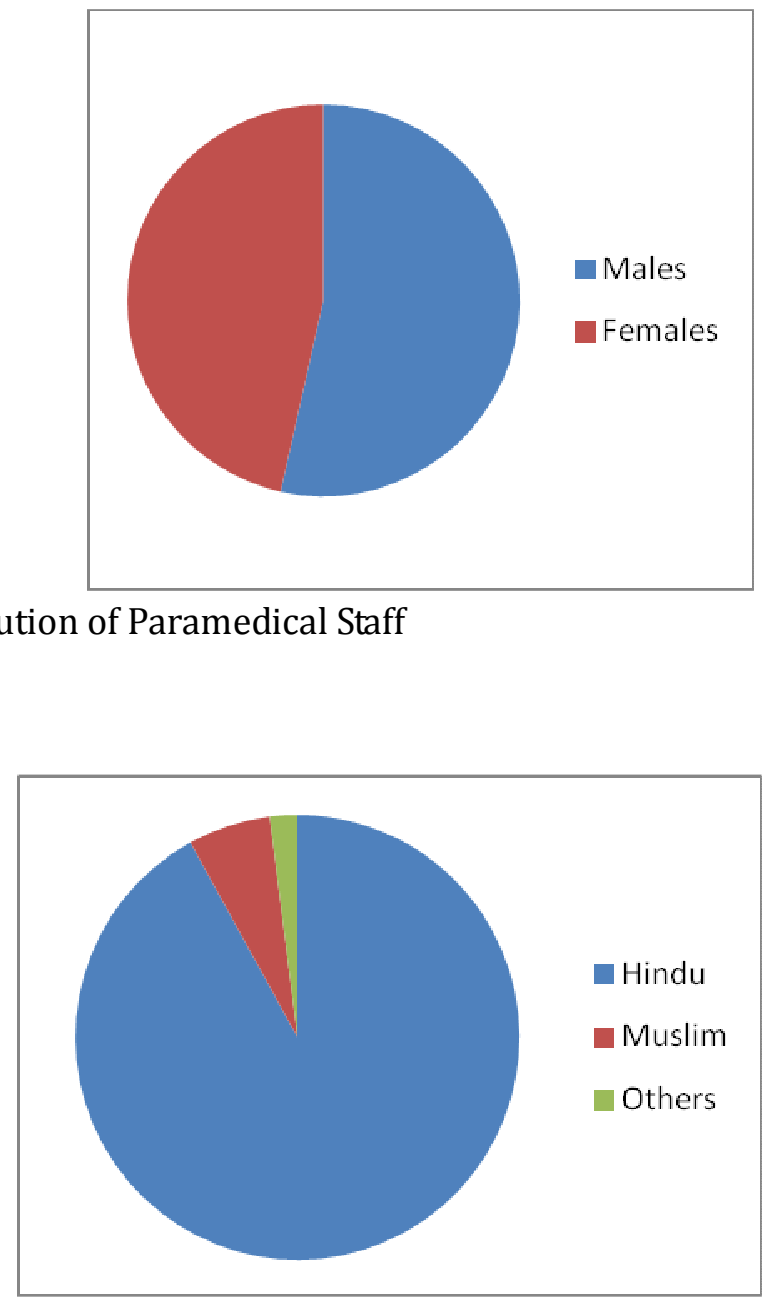

CHART 2: Religion wise distribution of paramedical staff 


\section{ORIGINAL ARTICLE}

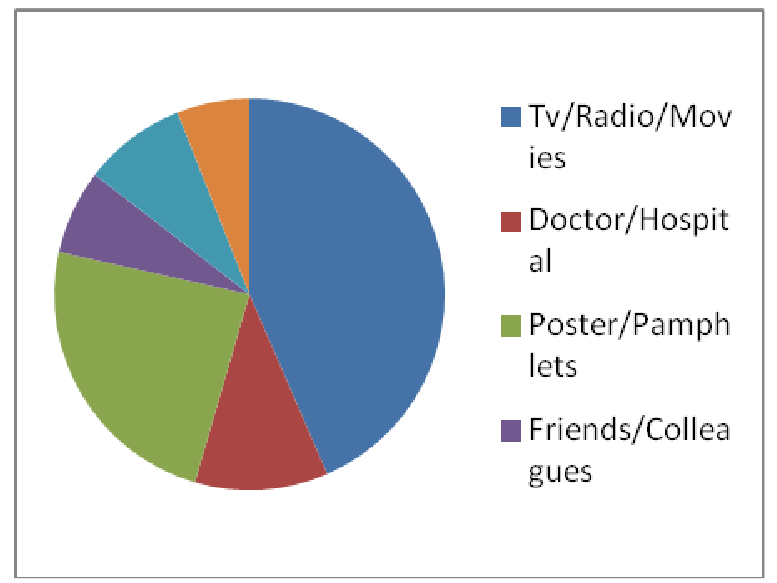

CHART 3: Common Source of information on eye donation.

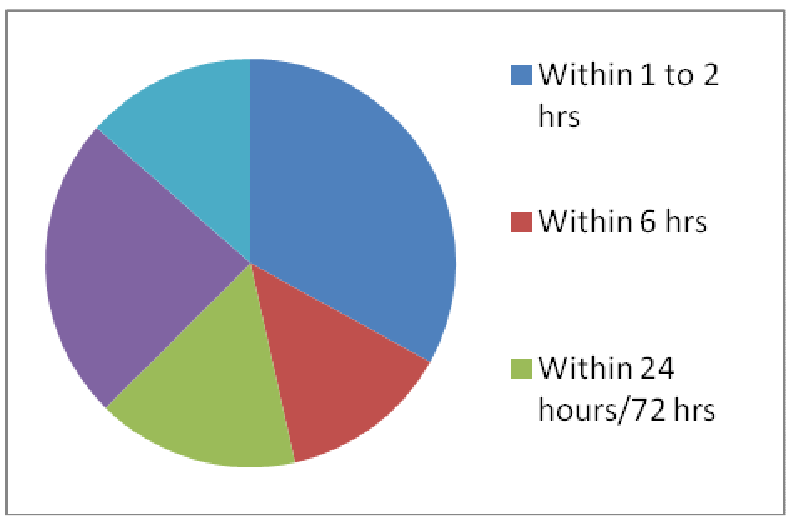

CHART 4: Knowledge about Ideal Time for Eye Donation

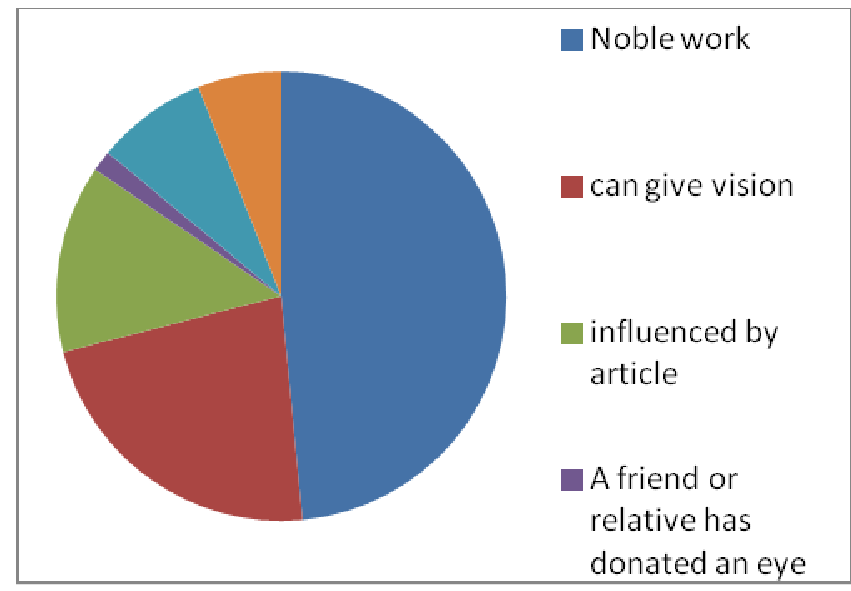

CHART 5: Distribution of perceived reasons for donating eyes by donors 